\title{
Potensi lestari dan tingkat pemanfaatan ikan selar (Atule mate) yang didaratkan di Desa Kelong, Kabupaten Bintan, Indonesia
}

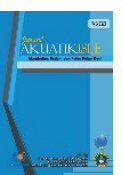

\section{The sustainable potential and utilization rate of Yellowtail scad fish (Atule mate) landed on Kelong Village, Bintan Regency, Indonesia}

\author{
Ageng Nur Agustins Zahra, Susiana, Dedy Kurniawan ${ }^{凶}$
}

Department of Aquatic Resources Management, Faculty of Fisheries and Marine Sciences, Raja Ali Haji Maritime University. Jln. Politeknik Senggarang, Tanjung Pinang, Kepulauan Riau 29111, Indonesia.

\author{
Ð Info Artikel: \\ Diterima: 29 Juli 2019 \\ Disetujui: 08 November 2019 \\ Dipublikasi: 10 November 2019 \\ Qd Keyword: \\ Yellowtail scad fish; MSY; \\ Utilization Rate; Bintan \\ $\varangle$ Korespondensi: \\ Dedy Kurniawan \\ Program Studi Manajemen \\ Sumberdaya Perairan, Universitas \\ Maritim Raja Ali Haji, Jln Politeknik \\ Senggarang, Tanjung Pinang, \\ Indonesia 29111 \\ Email: dedykurniawan@umrah.ac.id
}

\begin{abstract}
ABSTRAK. Ikan selar merupakan ikan bernilai ekonomis. Ikan selar banyak ditangkap oleh nelayan Desa Kelong. Salah satu daerah penangkapan ikan selar di Bintan yaitu Perairan Merapas. Jika penangkapan ikan selar dilakukan secara terus menerus tanpa mempertimbangkan stok ikan di alam, maka akan terjadi penangkapan yang berlebihan. Penelitian ini bertujuan untuk mengetahui potensi lestari maksimum(MSY), tingkat, dan upaya pemanfaatan, serta jumlah yang diperbolehkan (JTB) dalam penangkapan ikan selar di Perairan Merapas yang didaratkan di Desa Kelong. Alat tangkap yang digunakan nelayan Desa Kelong untuk menangkap ikan selar yaitu pancing ulur. Penelitian menggunakan metode survei. Data primer primer penelitian berupa hasil tangkapan dan upaya penangkapan. Data sekunder didapat dari wawancara nelayan dan literatur terkait. Analisis data menggunakan metode Schaefer. Hasil penelitian menunjukkan bahwa nilai potensi MSY sebesar 2501,37 kg/bulan dengan upaya optimum (f opt) sebesar 178 trip. Tingkat pemanfaatan ikan selar yaitu 38,48\% dan tingkat pengupayaan sebesar 22,16\%. Nilai JTB ikan selar yaitu 2001,1 kg. Secara keseluruhan, penangkapan ikan selar belum mencapai overfishing sehingga masih dapat dioptimalkan upaya penangkapannya.
\end{abstract}

ABSTRACT. Yellowtail scad fish was an economic value fish that many fishermen in Kelong Village catch. One of fishing ground in Bintan was Merapas Waters. Fishing activities without considering fish stocks in nature will caused overfishing. The objective of this research was to determine the Maximum Sustainable Yield (MSY), rate and effort of utilization, and Total Allowed Catch (TAC) of Yellowtail Scad fish in Merapas waters landed on Kelong Village. The fishing gear that Fishermen in Kelong Village used to catch Yellowtail Scad fish was hand line. This research used survey method. Primary data from this research were catch and effort of Yellowtail Scad Fish, while secondary data obtained from fishermen interviews and related literature. Data analysis of this research used Schaefer method. The result of this research was the potential value of MSY is 2,501.37 $\mathrm{kg} / \mathrm{month}$ with the optimum effort (f opt) 178 trip. The utilization rate of Yellowtail Scad fish was 38.48\% and effort rate of Yellowtail Scad fish was 22.16\%. Total allowed catch value of Yellowtail Scad fish was 2,001.1 kg. Overall, the catch of Yellowtail Scad Fish hasn' $t$ reach overfishing, so the fishing effort can be more optimized.

Copyright $\odot$ November 2019 Zahra, A.N.A., Susiana \& Kurniawan, D. Under Licence a Creative Commons Attribution-ShareAlike 4.0 International License

\section{Pendahuluan}

Kabupaten Bintan merupakan salah satu kabupaten di Provinsi Kepulauan Riau yang sangat potensial dibidang perikanan. Berdasarkan data Dinas Kelautan dan Perikanan Provinsi Kepulauan Riau tahun 2011, potensi sumberdaya ikan di Kabupaten Bintan mencapai 165.956,85 ton per tahun, dengan potensi sumberdaya ikan pelagis besar adalah $10.374,56$ ton per tahun, ikan pelagis kecil $97.575,50$ ton per tahun dan ikan demersal adalah 563,60 ton per tahun (Jumsurizal et al., 2014). Kecamatan Bintan Pesisir merupakan penghasil perikanan di Kabupaten Bintan. Salah satu wilayah di Kecamatan Bintan Pesisir yang memiliki potensi di bidang perikanan yaitu Desa Kelong.

Menurut keterangan warga setempat, Desa Kelong sering disebut sebagai desa nelayan, karena sebagian besar penduduk Desa Kelong berprofesi sebagai nelayan. Hasil tangkapan nelayan Desa Kelong berupa ikan, baik di daerah pelagis maupun demersal. Hasil tangkapan nelayan selanjutnya dikumpulkan ke gudang ikan, baik di Desa Kelong itu sendiri maupun di luar wilayah Desa Kelong, seperti Kijang, Batam, dan Tanjungpinang. 
Jenis-jenis ikan pelagis yang ditangkap nelayan Desa Kelong terdapat 5 famili dan 14 spesies, diantaranya famili Carangidae yang terdiri atas ikan seliap (Scomberoides tol), ikan selar papan (Alepes vari), ikan selar (Atule mate), ikan pelata (Selaroides leptolepis), ikan bulat (Carangoides plagiotaenia), ikan benggol (Decapterus ruselli), ikan putih (Carangoides ciliaris), famili Scombridae yaitu ikan tenggiri (Scomberomorus commerson), ikan tongkol (Euthynnus affinis), ikan selikur (Scomber australasicus), ikan kembung (Rastrelliger kanagurta), famili Menidae yaitu ikan parang (Mene maculata), famili Sphyraenidae yaitu ikan barakuda (Sphyraena flavicauda), dan famili Clupeidae yaitu ikan tamban (Sardinella lemuru). Salah satu ikan pelagis yang paling banyak ditangkap nelayan Desa Kelong yaitu ikan selar. Ikan selar merupakan salah satu jenis ikan pelagis kecil, yang membentuk gerombolan (scholling) dan mempunyai sifat berenang bebas dengan melakukan migrasi secara vertikal dan horizontal yang mendekati permukaan dengan ukuran tubuh relatif kecil (Ernaningsih, 2013).

Ikan selar memiliki nilai ekonomis dan populer di kalangan masyarakat karena memiliki cita rasa yang enak. Ikan selar di Desa Kelong berkisar antara Rp. 35.000,- sampai dengan Rp. 45.000,- per kilogram. Harga ikan selar di Kota Tanjungpinang berkisar antara Rp. 45.000-Rp. 60.000,- per kilogram. Nilai ekonomis yang tinggi dari ikan selar telah meningkatkan permintaan pasar, sehingga menjadikan ikan ini sebagai salah satu target utama penangkapan (Mas'ud, 2015).

Apabila permintaan ikan selar semakin tinggi akan mengakibatkan jumlah penangkapan ikan selar akan semakin tinggi pula. Jika dilakukan penangkapan terusmenerus tanpa memperhatikan pemulihan stok ikan, maka akan terjadi penangkapan yang berlebihan atau overfishing. Stok ikan selar kuning di Perairan Selat Sunda diduga telah mengalami penangkapan berlebihan (overfishing) (Sharfina, 2014). Analisis potensi ikan dimaksudkan untuk memberikan informasi tentang kelimpahan stok ikan di suatu perairan, rekomendasi jumlah upaya penangkapan yang optimum, dan jumlah tangkapan ikan yang diperbolehkan (Mahmud et al., 2015). Penelitan tentang potensi lestari dan tingkat pemanfaatan sumberdaya ikan di suatu perairan sangat penting untuk mengawasi tingkat eksploitasi kegiatan penangkapan ikan yang dilakukan di perairan tersebut (Nugraha et al., 2012).

Oleh karena itu penelitian ini bertujuan untuk mengetahui potensi lestari maksimum (MSY), tingkat dan upaya pemanfaatan, Jumlah Tangkap yang diperbolehkan (JTB) dalam penangkapan ikan selar di Perairan Merapas yang didaratkan di Desa Kelong. Penelitian ini juga perlu dilakukan sebagai salah satu langkah dalam aktivitas pengelolaan sumberdaya ikan berkelanjutan.

\section{Bahan dan Metode}

\subsection{Waktu dan Tempat}

Penelitian dilaksanakan pada bulan Agustus 2018 - Juli 2019. Pengambilan data ikan selar dilakukan di Gudang ikan Desa Kelong Kecamatan Bintan Pesisir Kabupaten Bintan (Gambar 1.). Pada Gambar 1., menunjukkan lokasi tempat pendaratan ikan dan prediksi daerah penangkapan ikan selar di Perairan Merapas.

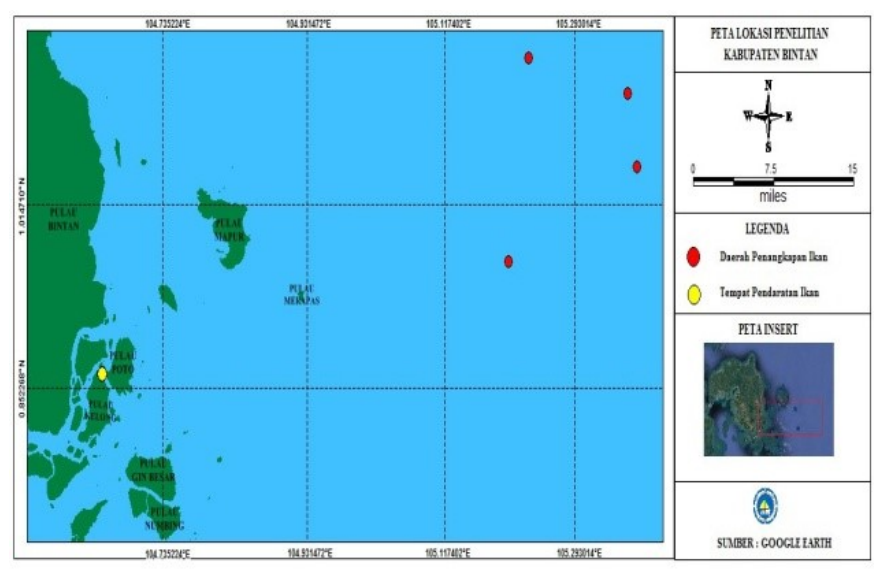

Gambar 1. Peta Lokasi Penelitian.

Daerah penangkapan ikan nelayan Desa Kelong ditunjukkan pada Gambar 2 sesuai titik koordinat yang diperoleh dari nelayan Desa Kelong berdasarkan peletakan rumpon.

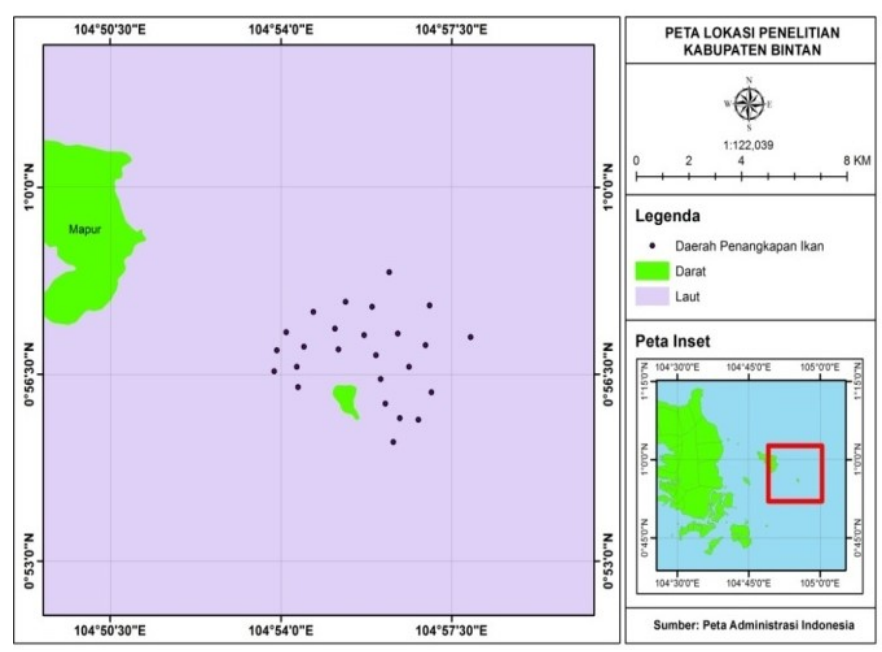

Gambar 2. Peta Lokasi Penelitian.

\subsection{Alat dan Bahan}

Alat yang digunakan pada penelitian ini yaitu alat tulis untuk mencatat data yang diambil dari lokasi penelitian, GPS (Global Positioning System) untuk menentukan titik koordinat lokasi pengambilan data, dan kamera untuk keperluan dokumentasi. Sedangkan bahan yang digunakan yaitu ikan selar sebagai objek penelitian.

\subsection{Prosedur Penelitian}

Metode yang digunakan pada penelitian ini yaitu metode survei dengan cara pengamatan langsung di lokasi penelitian dan wawancara. Data yang diambil pada penelitian ini meliputi data primer dan data sekunder. Data primer yang diambil yaitu jumlah produksi tangkapan (catch) dan upaya penangkapan (effort) ikan selar yang didapat dari gudang ikan, sedangkan data sekunder diperoleh dari data monografi dari kantor desa dan juga literatur terkait. Hasil pengolahan data penelitian disajikan dalam bentuk gambar. 


\subsection{Teknik Pengumpulan Data}

Pengumpulan data dilakukan melalui survei lapangan ke gudang ikan di Desa Kelong untuk pengambilan data primer penelitian. Selanjutnya melakukan wawancara menggunakan kuisoner ke nelayan, anak buah yang bekerja di gudang ikan dan pemilik gudang ikan (tauke) di Desa Kelong untuk mendapatkan informasi berupa hasil tangkapan ikan selar, jumlah trip, jenis armada, dan alat tangkap di perairan Merapas. Data sekunder berupa data monografi desa didapatkan dari Kantor Desa Kelong.

\subsection{Analisis Data}

Data yang diperoleh diolah menggunakan Excel 2017. Hasil pengolahan data kemudian dianalisis secara deskriptif untuk menjelaskan potensi lestari ikan selar dan analisis kuantitatif digunakan untuk menghitung nilai potensi tangkapan maksimum lestari (MSY) ikan selar. Analisis data kuantitatif menggunakan metode Surplus Produksi Schaefer untuk mengetahui nilai potensi lestari maksimum (maximum sustainable yield, MSY), tingkat pemanfaatan, tingkat pengupayaan, dan jumlah tangkapan yang diperbolehkan (JTB) ikan selar yang didaratkan di Desa Kelong. Analisis data yang digunakan pada penelitian ini yaitu Catch Per Unit Effort (CPUE), Nilai Potensi Lestari Maksimum (MSY), Tingkat Pemanfaatan, dan Tingkat Pengupayaan, serta Jumlah Tangkapan yang Diperbolehkan (JTB).

\subsubsection{Catch Unit Per Effort (CPUE)}

Menurut Sparre \& Venema (1998), perhitungan nilai CPUE dapat menggunakan rumus:

$$
\operatorname{CPUE}_{(\mathrm{I})}=\frac{\operatorname{catch}_{(\mathrm{i})}}{\mathrm{F}_{(\mathrm{s})}}
$$

Keterangan: CPUE (i) = hasil tangkapan per satuan upaya penangkapan pada bulan ke-i (kg/trip); Catch (i) = total hasil tangkapan pada bulan ke-i $(\mathrm{kg})$; dan $\mathrm{F}(\mathrm{s})=$ total upaya penangkapan standar (trip).

\subsubsection{Nilai Potensi Lestari Maksimum (Maximum Sustainable Yield-MSY)}

Untuk menduga besarnya MSY sumberdaya perikanan dan upaya penangkapan optimal dapat digunakan model Schaefer. Besarnya parameter $a$ dan $b$ secara matematik menggunakan persamaan regresi linier antara CPUE dan effort menggunakan Excel, dengan rumus:

$$
\mathrm{Y}=\mathrm{a}+\mathrm{bX}
$$

Keterangan: Y: variabel terikat (CPUE); X: variabel bebas (trip); Parameter a: intercept (garis yang memotong sumbu Y); Parameter $\mathrm{b}$ : slope (kemiringan garis regresi).

Menurut Wahyudi (2010), pada model Schaefer hanya berlaku jika nilai parameter (b) bernilai negatif, artinya dalam setiap penambahan upaya penangkapan akan menyebabkan terjadinya penurunan nilai CPUE. Jika dalam perhitungan diperoleh nilai koefisien (b) positif, maka perhitungan potensi dan upaya penangkapan optimum tidak perlu dilanjutkan, karena hal ini mengindikasikan bahwa penambahan upaya penangkapan masih memungkinkan untuk meningkatkan hasil tangkapan.

Upaya optimum adalah upaya penangkapan yang dapat dilakukan oleh suatu unit penangkapan untuk mendapatkan hasil tangkapan yang optimal tanpa merusak kelestarian sumberdaya perikanan tersebut (Rosana \& Prasita, 2015).

Untuk menentukan nilai optimum MSY model Schaefer dapat dihitung dengan rumus:

$$
\text { Fopt }=-\left(\frac{a}{2 b}\right)
$$

Sedangkan nilai potensi lestari maksimum (MSY) dapat dihitung dengan rumus:

$$
M S Y=\frac{-a^{2}}{4 b}
$$

\subsubsection{Tingkat Pemanfaatan Sumberdaya Ikan}

Nilai dari tingkat pemanfaatan menggunakan rumus:

$$
\mathrm{TP}=\frac{\mathrm{Ci}}{\mathrm{MSY}} \times 100 \%
$$

Keterangan: $\mathrm{TP}=$ Tingkat pemanfaatan (\%); $\mathrm{Ci}=$ Hasil tangkapan ikan pada periode $\mathrm{ke}-\mathrm{i}(\mathrm{kg})$; MSY = Maximum Sustainable Yield (kg/bulan).

Selain mengetahui tingkat pemanfaatan, maka perlu diketahui pula tingkat pengupayaan. Rumus yang digunakan untuk mengetahui tingkat pengupayaan, sebagai berikut:

$$
\mathrm{TPe}=\left(\frac{\mathrm{Ei}}{\mathrm{F}_{\mathrm{opt}} \mathrm{MSY}}\right) \times 100 \%
$$

Keterangan: $\mathrm{TPe}=$ Tingkat pengupayaan (\%); $\mathrm{Ei}=$ Upaya penangkapan periode ke-i (trip); Fopt MSY = Upaya optimum (trip).

\subsubsection{Jumlah Tangkapan yang Diperoleh (JTB)}

Untuk menghitung JTB (Jumlah Tangkap yang diperbolehkan) menggunakan rumus sebagai berikut:

$$
\mathrm{JTB}=80 \% x M S Y
$$

\section{Hasil dan Pembahasan}

\subsection{Produksi (Catch) dan Upaya Penangkapan (Effort)}

Produksi (catch) ikan selar cenderung mengalami perubahan yang berfluktuasi. Tangkapan tertinggi terjadi pada bulan Desember dan terendah terjadi pada Bulan Februari (Tabel 1). Hal ini sejalan dengan penelitian Sriyani et al. (2017) yang menyatakan bahwa puncak musim penangkapan ikan umumnya terjadi mulai bulan Desember. Menurut Nugraha et al. (2012), fluktuasi hasil tangkapan ikan banyak dipengaruhi oleh beberapa faktor antara lain keberadaan ikan, jumlah upaya penangkapan, dan tingkat keberhasilan operasi penangkapan. 
Tabel 1. Catch dan Effort Ikan Selar

\begin{tabular}{lcc}
\hline \multicolumn{1}{c}{ Waktu Penangkapan } & $\begin{array}{c}\text { Catch } \\
(\mathbf{k g})\end{array}$ & $\begin{array}{c}\text { Effort } \\
\text { (trip) }\end{array}$ \\
\hline Agustus & 1248,5 & 29 \\
September & 464,7 & 36 \\
Oktober & 758,4 & 67 \\
November & 1684,4 & 67 \\
Desember & 2376,6 & 47 \\
Januari & 569,2 & 21 \\
Februari & 405,7 & 34 \\
Maret & 415,5 & 20 \\
April & 738,8 & 34 \\
\hline
\end{tabular}

Ikan pelagis melakukan migrasi bertujuan untuk mencari makan, melindungi diri dari musuh, dan melakukan pemijahan. Menurut Kingston et al. (1999), ikan selar merupakan ikan pemakan krustasea dan ikan-ikan kecil.

Penyebaran ikan pelagis secara horizontal banyak dipengaruhi oleh pengaruh daratan sehingga ikan-ikan pelagis banyak ditemukan pada daerah neritik, yaitu daerah yang mencakup massa air yang terletak di paparan benua. Daerah ini banyak mendapatkan pengaruh daratan berupa unsur hara yang merupakan makanan yang disukai oleh ikan-ikan pelagis. Daerah ini juga tidak terlalu dalam sehingga perairannya cenderung lebih hangat (Abdilah, 2002).

Pada tahap migrasi/penyebaran ikan pelagis sangat dipengaruhi oleh faktor kekinian oseanografis setempat (Cahya et al., 2013). Salah satu faktor oseanografisnya yaitu arus. Arus merupakan parameter fisika perairan yang berpengaruh secara langsung maupun tidak langsung terhadap ekosistem laut dan biota yang hidup didalamnya, termasuk menentukan pola migrasi ikan. Ikan pelagis kecil akan memberikan respon pasif apabila berada dalam arus yang memiliki kecepatan sedang, sedangkan pada kecepatan arus yang rendah, ikan pelagis kecil akan bereaksi secara aktif (melawan arus). Dan pada kecepatan arus yang cepat, ikan pelagis kecil cenderung menghindar (Jalil, 2013). Kemungkinan pada saat Bulan Desember arus sedang kuat, sehingga ikan selar yang sedang bermigrasi ke sekitar Perairan Merapas terjebak dan tertangkap nelayan. Hal ini diduga menyebabkan hasil tangkapan pada Bulan Desember lebih tinggi dibandingkan hasil tangkapan di bulan lainnya.

Upaya tangkapan ikan selar juga mengalami fluktuasi. Pada bulan Agustus hingga November effort terus mengalami peningkatan dan mulai mengalami penurunan pada bulan Desember dan Januari. Upaya penangkapan pada bulan Februari hingga April yang jumlahnya naik-turun. Effort tertinggi yaitu pada 2 bulan berturut-turut yaitu bulan Oktober dan November. Hal ini dapat terjadi disebabkan oleh faktor kondisi alam yang mendukung, serta ketersediaan modal para nelayan yang cukup untuk melaut. Sedangkan effort terendah terjadi pada bulan Maret. Pada bulan Januari juga memiliki effort rendah, hal ini disebabkan pada bulan Januari merupakan musim angin utara dimana cuaca kurang baik sehingga nelayan tidak banyak melakukan aktivitas penangkapan ikan dengan demikian mengakibatkan upaya penangkapan/effort menurun drastis.

\subsection{Catch Per Unit Effort (CPUE)}

Hasil tangkapan per satuan upaya penangkapan atau Catch Per Unit Effort (CPUE) sangat penting dalam pengawasan dan pengendalian penangkapan ikan. Penghitungan CPUE dalam sumberdaya perikanan bertujuan untuk mengetahui tingkat pemanfaatan ikan dan perkembangan produksi tangkapan ikan yang didaratkan (Telussa, 2016). Jumlah produksi tangkapan pada prinsipnya adalah output dari kegiatan penangkapan, sedangkan upaya penangkapan/ effort yang diperlukan merupakan input dari kegiatan penangkapan (Noordiningroom et al., 2012).

Berdasarkan hasil analisis data menunjukkan bahwa Nilai tertinggi CPUE terjadi pada bulan Desember sebesar $50,57 \mathrm{~kg} /$ trip, sedangkan nilai terendah ada pada bulan Oktober yaitu sebesar 11,32 kg/trip. Nilai CPUE menggambarkan tingkat produktivitas dari upaya penangkapan (effort) (Gambar 3).

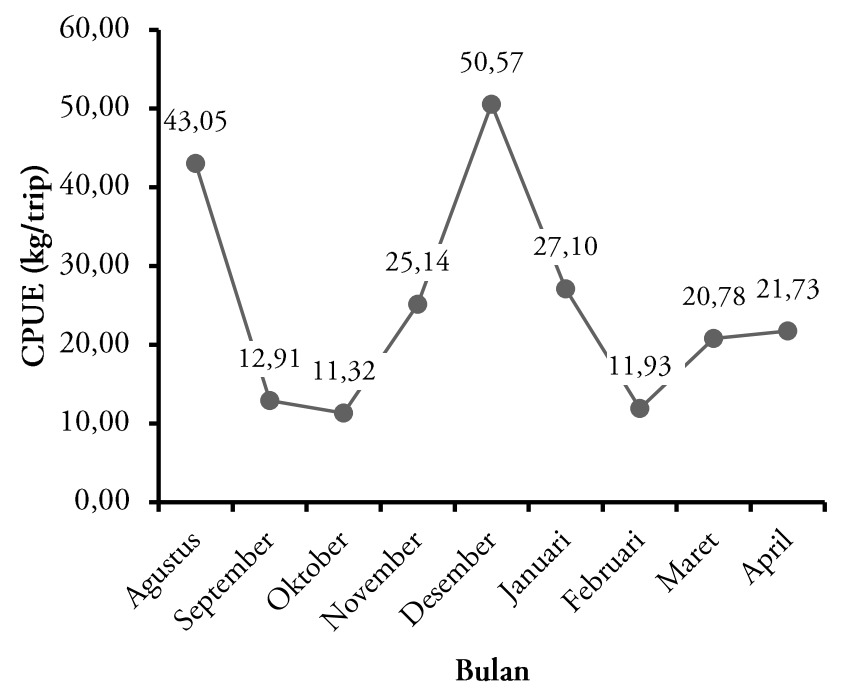

Gambar 3. Nilai CPUE Ikan Selar yang Didaratkan di Desa Kelong.

Setelah mengetahui fluktuasi nilai CPUE, maka perlu diketahui hubungan antara nilai CPUE dengan effort (Aminah, 2011). Penurunan nilai CPUE yang disebabkan karena kenaikan upaya penangkapan, juga berpengaruh terhadap hubungan antara catch, dengan mengaitkan antara effort dan catch dapat diketahui kecenderungan fluktuasinya (Telussa, 2016).

Berdasarkan hasil regresi didapatkan bentuk persamaan linier $\mathrm{Y}=28,05-0,08 \mathrm{X}\left(\mathrm{R}^{2}=0,01\right)$. Persamaan tersebut menunjukkan bahwa konstanta (a) sebesar 28,05 menyatakan bahwa jika tidak ada penambahan effort, maka potensi yang tersedia di alam masih sebesar 28,05 kg/trip. Koefisien regresi b sebesar -0,08 menyatakan hubungan negatif antara produksi dengan effort bahwa setiap pengurangan 1 trip effort akan menyebabkan kenaikan CPUE sebesar 0,08 kg/trip, begitu pula sebaliknya. Jika semakin besar effort maka nilai CPUE juga akan berkurang, artinya bahwa CPUE berbanding lurus dengan effort. Peningkatan upaya penangkapan sebesar satu satuan akan berakibat terjadinya penurunan hasil tangkapan (produksi) (Susiana \& Rochmady, 2018). 


\subsection{Potensi Lestari Maksimum (MSY)}

Menurut Telussa (2016), produksi tangkapan maksimum lestari adalah besarnya jumlah ikan yang dapat ditangkap secara terus menerus dari suatu sumberdaya tanpa mempengaruhi kelestarian stok ikan. Sedangkan upaya penangkapan optimum (fopt) adalah besarnya upaya penangkapan yang dilakukan oleh unit penangkapan, agar mendapatkan hasil yang maksimal, tanpa merusak kelestarian sumberdaya ikan yang ada.

Potensi lestari suatu sumberdaya khususnya sumberdaya perairan dapat didekati dengan model schaefer dan Fox. Kedua model ini efektif dapat mengestimasi potensi lestari sumberdaya dengan mengabaikan faktor-faktor biologis sumberdaya. Namun demikian beberapa syarat penggunaan analisis estimasi potensi lestari tetap harus menjadi perhatian diantaranya kecukupan data dan informasi yang digunakan (Susiana \& Rochmady, 2018). Pada penelitian ini, analisis data digunakan dengan model Schaefer.

Nilai intercept (a) dan X variabel (b) yang didapat dari persamaan regresi linier diperlukan untuk menduga nilai MSY dan Fopt dengan menggunakan model model Schaefer.

Tabel 2. Nilai a, b, MSY, dan Fopt penangkapan ikan selar di perairan Merapas, Kabupaten Bintan.

\begin{tabular}{lc}
\hline \multicolumn{1}{c}{ Komponen Penilaian } & Model Schaefer \\
\hline $\mathrm{a}$ & 28,05 \\
$\mathrm{~b}$ & $-0,08$ \\
MSY & $2501,37 \mathrm{~kg} / \mathrm{bulan}$ \\
$\mathrm{F}_{\text {opt }}$ & 178 trip \\
\hline
\end{tabular}

Berdasarkan Tabel 2, dengan pendekatan model Schaefer diketahui nilai intercept (a) sebesar 28,34 dan slope (b) sebesar -0,08 membentuk persamaan linier $Y=28,05-$ 0,08X sehingga didapatkan nilai MSY dengan pendekatan model Schaefer sebesar 2.501,37 kg per bulan dengan $\mathrm{f} \mathrm{opt}$ sebesar 178 trip.

Setelah mengetahui nilai MSY maka tingkat pemanfaatan suatu sumberdaya ikan diharapkan tidak melebihi nilai MSY-nya agar tetap terjaga kelestarian sumberdayanya. Manfaat dilakukannya pendugaan tingkat upaya penangkapan yang optimum adalah agar kerugian waktu, tenaga, dan biaya operasi penangkapan dapat diperkecil dan usaha penangkapan yang dilakukan diharapkan akan selalu mencapai hasil yang optimal (Irhamsyah et al., 2013). Agar upaya penangkapan dapat optimum maka perlu dilakukan pengalokasian jumlah upaya penangkapan menurut daerah penangkapan ikan dan musim penangkapan (Cahyani et al., 2013).

Berdasarkan data pada Tabel 1 dan Gambar 4, nilai catch ikan selar yang di daratkan pada Bulan Desember mendekati nilai MSY yaitu sebesar $2376,6 \mathrm{~kg}$. Hal ini diduga pada saat Bulan Desember ikan selar sedang bermigrasi ke Perairan Merapas yang merupakan daerah penangkapan ikan selar. Sedangkan untuk waktu penangkapan lainnya, nilai catch cenderung jauh dari nilai MSY, hal ini mengindikasikan bahwa kegiatan penangkapan ikan selar oleh nelayan Desa Kelong belum mencapai tingkat overfishing. Dengan demikian upaya penangkapan ikan selar di perairan Merapas dapat ditingkatkan.

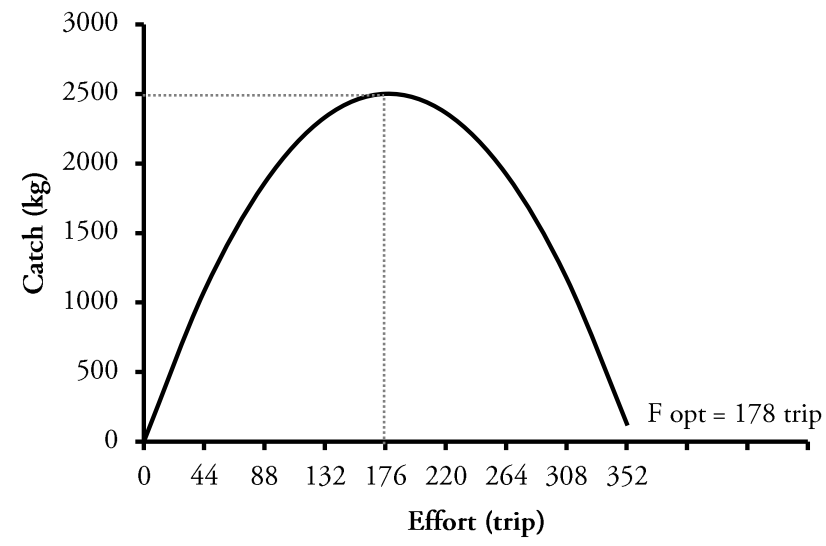

Gambar 4. Nilai Potensi Lestari Maksimum (MSY) Ikan Selar yang Didaratkan di Desa Kelong.

\subsection{Tingkat Pemanfaatan dan Tingkat Pengupayaan}

Tingkat pemanfaatan sumberdaya ikan dapat diketahui dengan cara menghitung proporsi jumlah produksi tangkapan pada periode tertentu dari nilai produksi maksimum lestari (MSY) (Aminah, 2011). Tingkat pemanfaatan yang melebihi potensi lestari maksimum (MSY) dapat mengancam kelestarian sumberdaya ikan, ketersediaan stok ikan dan keberlangsungan siklus hidupnya akan terganggu yang pada akhirnya stok ikan akan semakin sedikit (Simbolon et al., 2011).

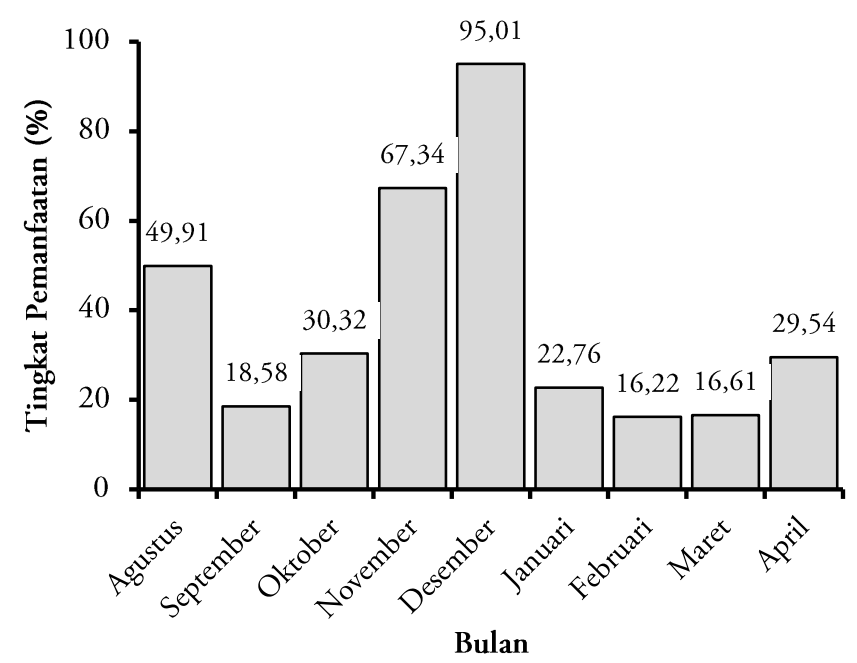

Gambar 5. Nilai tingkat pemanfaatan ikan selar yang didaratkan di Desa Kelong, Kabupaten Bintan.

Berdasarkan Gambar 5, Tingkat Pemanfaatan (TP) tertinggi terjadi pada bulan Desember yaitu sebesar 95,01\%. Nilai TP tersebut tergolong tinggi oleh karena karena mendekati nilai MSY, akan tetapi masih dikategorikan tingkat pemanfaatan yang optimum. Sedangkan nilai TP terendah terdapat pada bulan Maret yaitu sebesar 16,61\%. Rata-rata tingkat pemanfaatan ikan selar di Perairan Merapas yang di daratkan di Desa Kelong yaitu sebesar $38,48 \%$.

Tingkat pengupayaan alat tangkap didapatkan setelah mengetahui tingkat upaya optimum. Tingkat pengupayaan dihitung dengan mempersenkan jumlah upaya penangkapan 
pada tahun tertentu terhadap nilai upaya penangkapan optimum.

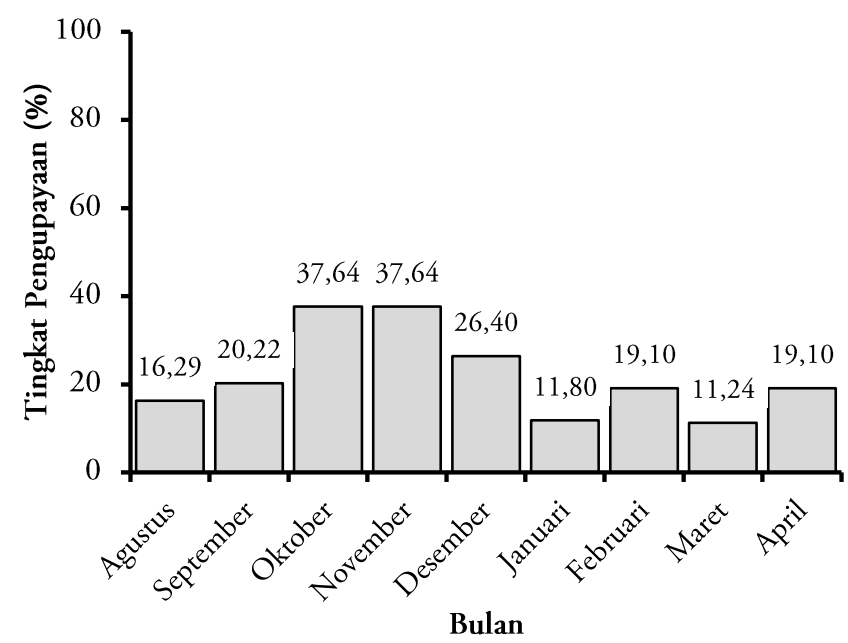

Gambar 6. Nilai tingkat pengupayaan ikan selar yang didaratkan di Desa Kelong, Kabupaten Bintan.

Nilai Tingkat Pengupayaan (TPe) (Gambar 6) ikan selar di Perairan Merapas yang didaratkan di Desa Kelong tertinggi pada bulan Oktober dan November, yaitu sebesar 37,64\%. Hal ini disebabkan pada bulan November jumlah upaya tangkap (effort) tertinggi diantara waktu penangkapan lainnya. Sedangkan nilai TPe terendah ada pada bulan Maret yaitu sebesar $11,24 \%$ dikarenakan pada bulan Maret jumlah effort paling sedikit dibanding effort pada waktu penangkapan lainnya. Rata-rata tingkat pengupayaan ikan selar di Perairan Merapas yang di daratkan di Desa Kelong yaitu sebesar $22,16 \%$.

\subsection{Jumlah Tangkapan yang Diperbolehkan (JTB)}

Menurut Triyono (2013), JTB dapat didefinisikan sebagai bentuk pengelolaan suatu perairan melalui penetapan jumlah produksi tangkapan ikan berdasarkan evaluasi dan pertimbangan secara teknis, biologis, ekonomis, dan sosial. Tujuan utama JTB yaitu mengatur jumlah penangkapan agar tidak melebihi daya dukung sumberdaya ikan, sehingga pemanfaatanya dapat dilakukan secara berkelanjutan. Pemahaman tentang jumlah tangkapan yang diperbolehkan (JTB) tidak hanya mengontrol hasil tangkapan tetapi juga secara tidak langsung dapat mengontrol tingkat eksploitasi di bidang perikanan (Badiuzzaman et al., 2014).

Potensi ikan yang diperbolehkan untuk ditangkap adalah $80 \%$ dari nilai MSY, sehingga didapatkan nilai JTB sebesar $2.001,1 \mathrm{~kg}$. Berdasarkan data catch ikan selar yang didaratkan di Desa Kelong, pada bulan Desember didapatkan catch sebesar $2.376,6 \mathrm{~kg}$, yang artinya sudah melewati nilai JTB tetapi belum melebihi batas MSY. Namun, pada periode waktu penangkapan lainnya produksi tangkapan (catch) ikan selar belum mencapai nilai JTB. Hal ini berarti bahwa terbuka peluang untuk dapat dilakukan kegiatan penangkapan ikan secara optimal dengan meningkatkan upaya penangkapan.

Untuk menghindari terjadinya overfishing terhadap ikan selar di Perairan Merapas maka diperlukan kajian lebih lanjut mengenai penanganan dan pengawasan oleh pihak yang berkompeten terkait, terutama membatasi upaya penangkapan. Dan perlu dilakukan penelitian tentang pola pemijahan ikan selar (Atule mate), ukuran ikan selar yang layak tangkap, dan pengaruh faktor oseanografi terhadap hasil tangkapan ikan selar sehingga pengelolaan perikanan khususnya ikan selar lebih optimal.

\section{Simpulan}

Nilai potensi lestari maksimum (MSY) ikan selar di Perairan Merapas yang didaratkan di Desa Kelong yaitu $2.501,38 \mathrm{~kg}$ dengan upaya optimum (f opt) 178 trip. Rata-rata tingkat pemanfaatan ikan selar di Perairan Merapas yang didaratkan di Desa Kelong yaitu 38,48\% dan rata-rata tingkat pengupayaan yaitu 22,16\%. Nilai jumlah tangkapan yang diperbolehkan (JTB) yaitu 2001,1 kg. Hasil tangkapan ikan selar yang didaratkan di Desa Kelong secara keseluruhan masih dibawah nilai MSY. Nilai Tingkat Pemanfaatan dan Tingkat Pengupayaan ikan selar yang didaratkan di Desa Kelong masih dapat dioptimalkan.

\section{Ucapan Terima Kasih}

Penulis mengucapkan terimakasih yang sebesarbesarnya kepada seluruh pihak yang membantu jalannya penelitian ini. Terimakasih kepada Pihak Desa Kelong, Bapak So Tong dan Bapak Kar selaku pemilik gudang ikan yang telah bersedia bekerjasama untuk melakukan penelitian ini.

\section{Referensi}

Abdilah, B. 2002. Pengukuran Nilai Target Strength Ikan Pelagis dengan Menggunakan Sistem Akustik Bim Terbagi di Perairan Selat Makassar dan Laut Sulawesi. [Skripsi]. Institut Pertanian Bogor. Bogor.

Adnan. 2010. Analisis Suhu Permukaan Laut Dan Klorofil-A Data Inderaja Hubungannya dengan Hasil Tangkapan Ikan Tongkol (Euthynnus affinis) di Perairan Kalimantan Timur. Jurnal "Amanisal" PSP FPIK Unpatti-Ambon. 1(1): 1-12.

Aminah, S. 2011. Analisis Pemanfaatan Sumberdaya Ikan Kembung (Rastrelligerspp.) di Perairan Kabupaten Tanah Laut Provinsi Kalimantan Selatan. Fish Scientiae. 1(2): 179-189.

Badiuzzaman. Wijayanto, D., \& Yulianto, T. 2014. Analisis Potensi Tangkap Sumberdaya Rajungan (Blue Swimming Crab) di Perairan Demak. Journal of Fisheries Resources Utilization Management and Technology. 3(3): 248-256.

Cahya, N.C., Setyohadi,D., \& Surinati,D. 2017. Pengaruh Parameter Oseanografi Terhadap Distribusi Ikan. Jurnal Oseana. 41(4): 114.

Cahyani, R.T., Anggoro, S., \& Yulianto, B. 2013. Potensi Lestari Sumberdaya Ikan Demersal (Analisis Hasil Tangkapan Cantrang yang Didaratkan di TPI Wedung Demak). Prosiding Seminar Nasional Pengelolaan Sumberdaya Alam dan Lingkungan. Universitas Diponegoro. Semarang.

Ernaningsih, D. 2013. Analisis Bioekonomi Ikan Pelagis Kecil di Teluk Banten. Jurnal Ilmiah Satya Negara Indonesia. 1-9.

Irhamsyah, Azizah, N., \& Aulia, H. 2013. Tingkat Pemanfaatan dan Potensi Maksimum Lestari Sumberdaya Cumi-Cumi (Loligo sp.) di Kabupaten Tanah Bumbu Provinsi Kalimantan Selatan. Jurnal Buletin PSP. 21(2): 181-192.

Jalil, R. 2013. Distribusi Kecepatan Arus Pasang Surut pada Muson Peralihan Barat-Timur Terkait Hasil Tangkapan Ikan Pelagis Kecil di Perairan Spermonde. Jurnal Depik. 2(1): 26-32. 
Jumsurizal, Nelwan, A., \& Kurnia, M. 2014. Produktivitas Penangkapan Ikan Tenggiri (Scomberomorus commerson) Menggunakan Pancing Ulur di Perairan Kabupaten Bintan. Jurnal Ilmu Pengetahuan, Teknologi dan Seni Pemanfaatan Sumberdaya Perikanan. 1(2): 165-173.

Kingston, S.D., Venkataramani, V.K., \& Venkataramanujam, K. 1999. Food Habits and Feeding Intensity of Finlet Scad Atule mate (Teleostei) Off Gulf of Mannar, Southeast Cost of India. 28: 307-311.

Mahmud, A., Rita, \& Bubun, L. 2015. Potensi Lestari Ikan Layang (Decapterus spp.) Berdasarkan Hasil Tangkapan Pukat Cincin di Perairan Timur Sulawesi Tenggara. Jurnal Teknologi Perikanan dan Kelautan. 6(2): 159-168.

Mas'ud, F. 2015. Pengaruh Hasil Tangkapan Sumberdaya Ikan Selar Kuning (Selaroides leptolepis) yang didaratkan di PPI Desa Kranji Kecamatan Paciran Kabupaten Lamongan. Jurnal IImu Eksakta. 3(2): 1-26.

Noordiningroom, R., Anna, Z., \& Suryana, A.A.H. 2012. Analisis Bioekonomi Model Gordon-Schaefer Studi Kasus Pemanfaatann Ikan Nila (Oreochromis nilaticus) di Perairan Umum Waduk Cirata Kabupaten Cianjur Jawa Barat. Jurnal Kelautan dan Perikanan. 3(3): 263-274.

Nugraha, E., Koswara, B., \& Yuniarti. 2012. Potensi Lestari dan Tingkat Pemanfaatan Ikan Kurisi (Nemipterus japonicus) di Perairan Teluk Banten. Jurnal Perikanan dan Kelautan. 3(1): 91-98.

Rosana, N., \& Prasita,V.D. 2015. Potensi dan Tingkat Pemanfaatan Ikan sebagai Dasar Pengembangan Sektor Perikanan di Selatan Jawa Timur. Jurnal Kelautan. 8(2): 71-76.

Sharfina, M., Boer, M., \& Ernawati, Y. 2014. Potensi Lestari Ikan Selar Kuning (Selaroides leptolepis) di Perairan Selat Sunda. Marine Fisheries Journal. 5(1): 101-108.
Simbolon, D., Jeujanan, B., \& Wiyono, E.S. 2011. Efektivitas Pemanfaatan Rumpon Pada Operasi Penangkapan Ikan di Perairan Kei Kecil, Maluku Tenggara. Jurnal Marine Fisheries. 2(1): 19-28.

Sparre, P. \& Venema, S.C. 1998. Introduction to Tropical Fish Stock Assessment. Part 1. FAO Fish. Tech. Paper. Vol 306. 407 p.

Sriyani, Zen, L.W., \& Susiana. 2017. Potensi dan Tingkat Pemanfaatan Ikan Tongkol (Euthynnus sp.) yang Didaratkan di Desa Barek Motor Kecamatan Gunung Kijang Kabupaten Bintan Provinsi Kepulauan Riau. [Skripsi]. Universitas Maritim Raja Ali Haji. Tanjungpinang.

Susiana, S. \& Rochmady, R. 2018. Pendugaan Stok Cumi-cumi Loligo sp. di Perairan Kabupaten Pangkajene dan Kepulauan, Sulawesi Selatan, Indonesia. Jurnal Pengelolaan Perairan. 1(1): $28-44$.

Telussa, R.F. 2016. Kajian Stok Ikan Pelagis Kecil dengan Alat Tangkap Mini Purse Seine di Perairan Lempasing, Lampung. Jurnal Ilmiah Satya Mina Bahari. 1(1): 32-42.

Triyono, H. 2013. Metode Penetapan Jumlah Tangkapan yang Diperbolehkan (JTB) untuk Berbagai Jenis Sumberdaya Ikan di WPP-NKRI. Fisheries Recources Journal. Jakarta Fisheries University. Jakarta.

Wahyudi, H. 2010. Tingkat Pemanfaatan dan Pola Musim Penangkapan Ikan Lemuru (Sardinella Lemuru) di Perairan Selat Bali. [Skripsi]. Institut Pertanian Bogor. Bogor.

Ageng Nur Agustins Zahra, Department of Aquatic Resources Management, Faculty of Fisheries and Marine Sciences, Raja Ali Haji Maritime University. Jl. Politeknik Senggarang, Tanjung Pinang, Kepulauan Riau 29111, Indonesia. Email: agengnuragustinszahra@gmail.com

Susiana, Department of Aquatic Resources Management, Faculty of Fisheries and Marine Sciences, Raja Ali Haji Maritime University. Jl. Politeknik Senggarang, Tanjung Pinang, Kepulauan Riau 29111, Indonesia, Email: susiana@umrah.ac.id

URL ID-orcid: http://orcid.org/0000-0002-6792-0069

research-ID: http://www.researcherid.com/rid/E-7383-2017

URL Google Scholar: https://scholar.google.co.id/citations?user=HfXFCBMAAAAJ\&hl=id

URL Sinta Dikti: http://sinta2.ristekdikti.go.id/authors/detail/?id=5972812\&view=overview

Dedy Kurniawan, Department of Aquatic Resources Management, Faculty of Fisheries and Marine Sciences, Raja Ali Haji Maritime University. Jl. Politeknik Senggarang, Tanjung Pinang, Kepulauan Riau 29111, Indonesia. Email: dedykurniawan@umrah.ac.id URL Sinta Dikti: http://sinta2.ristekdikti.go.id/authors/detail?id=6022848\&view=overview

\section{How to cite this article:}

Zahra, A.N.A., Susiana, S. \& Kurniawan, D. 2019. The sustainable potential and utilization rate of Yellowtail scad fish (Atule mate) landed on Kelong Village, Bintan Regency, Indonesia, Akuatikisle: Jurnal Akuakultur, Pesisir dan Pulau-Pulau Kecil, 3(2): 57-63. DOI: https://dx.doi.org/10.29239/j.akuatikisle.3.2.57-63 